Notre Dame Journal of Formal Logic

Volume XIX, Number 1, January 1978

NDJFAM

\title{
APODICTIC TRUTH: HUSSERL'S EIDETIC REDUCTION VERSUS INDUCTION
}

\author{
JAMES PALERMO
}

The need to provide a clarification of the primordial structures of logic is a theme which recurs throughout Husserl's phenomenological corpus. What is involved here goes beyond the negative restrictions that attach validity to apophantic logic. Indeed, Husserl's phenomenology is a search for those a-priori subjective structures which appear with selfevidence and ground logic in apodictic truth. And to say this is to speak to what Husserl considered was the fundamental problematic of logic, namely, its "two-sidedness." In his own words:

On the one side, we have the question of constitution of forms [of judgment] and their laws and, on the other, that of the subjective conditions of the attainment of self-evidence. Here the act of judgment qua subjective activity comes into question, and with it the subjective processes in which formations, as they appear, manifest themselves. ... ${ }^{1}$

For Husserl, the resolution of this problematic is signaled by the arrival at the phenomenological goal of essential insight. But, Husserl stipulated that the phenomenological-transcendental and eidetic reductions are necessary pre-conditions for the achievement of that goal. ${ }^{2}$ Nevertheless, the innumerable misconceptions that have tainted the phenomenological enterprise testify to the failure of many to heed Husserl's stipulations. Indeed one of the most egregious errors has been the attempt to destroy the necessary disjunction between eidetic reduction and induction, and to

1. Edmund Husserl, Experience and Judgment, ed. by Ludwig Landgrebe, trans. by James S. Churchill and Karl Ameriks, Northwestern University Press, Evanston (1973), p. 17.

2. The phenomenological reduction involves the suspension of "the natural attitude." The eidetic reduction reveals logical structures which are universal pure essences. These essences appear with intuitive self-evidence conforming to a-priori essential laws. 
designate eidetic reduction as simply a more refined form of induction. Such arguments are two pronged: First, it is claimed that eidetic consciousness is neither adequate nor apodictic. Second, the source of this inadequacy is to be found in eidetic reduction which yields data contaminated by indeterminacy and ambiguity.

All of this I claim is wrongheaded. In this paper I shall argue that eidetic reduction cannot be collapsed into induction and that a modal disjunction separates the apperceptive mechanisms of eidetic consciousness and induction. This is because essences are the objects of eidetic consciousness; and, for Husserl, are claimed with apodicticity, i.e., are necessary, indubitable, and infallible. On the other hand, the objects of induction concern empirical particulars and as statements of naive realism are not necessary, but incomplete. In simplest terms, I shall argue that eidetic reduction and its goal of essential insight are radically different from the method of naive realism. My argument will be built upon uncovering the distinctions between immanent and morphological essences vis-à-vis empirical things, the acquistion of apodictic certitude, Husserl's use of the term, transcendence, and the relationships of space and time as they are revealed in eidetic reduction and induction. So that these distinctions may be laid out most directly I shall offer arguments which try to collapse eidetic reduction into the inductive mode and then demonstrate their falsity by appealing to the words of Husserl himself.

1 An apparently fundamental "problem" for the eidetic realm revolves about Husserl's use of the term, "transcendent," as it is applied first to spatio-temporal objects and then to the "same" empirical objects appearing in their reduced form as essences. Obviously such essences are (in one sense) dependent upon the sensory appearances of spatio-temporal facts. It, therefore, seems that essences are precluded from adequacy of outer perception. But to get at Husserl's usage of "transcendent" one must specify the kinds of objects he is considering, i.e., empirical objects as opposed to the differences among essences, themselves. The latter appear either as immanent or as morphological-transcendent essences. The difference between immanent and morphological-transcendent essences is this:

Transcendent "objects" mean essences of individual events which transcend consciousness, essences, therefore, of that which only constitutes itself-for instance, through sensory appearances as, indeed, consciousness requires. $^{3}$

By contrast, immanent essences are the formations of consciousness itself. Now with respect to the outer perception of empirical objects Husserl indicated:

3. Edmund Husserl, Ideas, translated from the German by W. R. Boyce Gibson, Collier-Macmillan, Ltd., London (1969), p. 164. 
A certain inadequacy belongs further to the perception of things . . . a thing is necessarily given in mere modes of appearing and the necessary factors in this case are a nucleus of what is 'really presented,' an outlaying zone of apprehension consisting of marginal code-data of an accessory kind and a vague more or less indeterminacy. ${ }^{4}$

Husserl goes on to say that the essential correlation of thing and thing perception remains ineradicably incomplete after this fashion:

A certain inadequacy belongs, further to perception of things, and that too is an essential necessity. In principle, a thing can be given only in one of its aspects, and that only means incompletely, in some sense or other imperfectly, but precisely that which presentation through perspectives prescribes. ${ }^{5}$

Now, the misuse of the term "transcendent" comes from failing to note Husserl's distinction between morphological-transcendent essences and facts. Spatio-temporal facts must not be equated with the eidetically reduced and transformed contents of spatio-temporal facts. Indeed, the former are transcendent to perception; or, as the term denotes, are precluded from adequacy of outer perception. But, morphological-transcendent essences must not be construed as "transcendent" in the same sense as spatio-temporal facts. This is because the mode of giveness of the morphological-transcendent essences are restricted by the sense data and the techniques of outer perception, although these essences are not restricted to the sense data or any techniques of outer perception. Such is the case for facts. Presently, we shall show morphological-transcendent essences are not facts.

2 A necessary distinction then between the essence and the empirical object is the a-temporal character of the former. Now, some critics hold that, since acts of intuition have a temporal location, essences themselves must be temporally located. The difficulty is handled by careful examination of the giveness of intuition, with special attention paid to the distinction between empirical and essential intuition. These two types differ "in principle" and correspondingly reveal the differences of essential relations as between fact and essence. The temporal location of acts of empirical intuition is not disputed. Husserl on this point says:

... of the first 'natural' sphere of knowledge and of all its sciences is natural experience, and the primordial dator experience is perception in the ordinary sense of the term. To have something real, primordially given, and to become aware of it and perceive it in simple intuition, are one and the same thing. ${ }^{6}$

4. Ibid., p. 125 .

5. Ibid.

6. Ibid., p. 45 . 
Husserl goes on to acknowledge that the sciences of experience (or fact) posit the real in individual form. This means the real fact, as the object of empirical intuition, has a

. . spatio-temporal existence, as something existing in this time spot, having this particular duration of its own and a real content which in its essence could just as well have been present in any other time spot. ${ }^{7}$

He adds, however, that empirical intuition can be transformed into essential intuition-

... A possibility which is itself not to be understood as empirical but as an essential possibility. The object of such insight is then the corresponding pure essence or eidos, whether it be the highest category or one of its specialization, right down to the fully concrete. ${ }^{8}$

Here it is crucially significant that the datum of an essential intuition be seen as a new type-a pure essence as contrasted to the datum of individual or empirical intuition-an individual object. ${ }^{9}$ To dispel confusion, Husserl insists that essential insight is still intuition, just as the eidetic object is still an object. It is, therefore, plain that the meaning of intuition is applicable to both empirical and essential intuition; and indeed essences are products of intuition. But intuition must be described in its 'pregnant sense' to include not only empirical but essential intuition as well.

Still, the objection that essences are temporally located is not overcome until we see that essences unlike empirical objects have phenomenological time as their setting. Empirical objects, by contrast, are revealed in objective or what Husserl calls "cosmic" or objective time. "Joy" is a typical example of objective time. It exhibits these characteristics: it can be measured and it has a beginning and ending. In Husserl's words

. . Every present moment of experience, be it even the terminal phase of the duration of an experience that is ceasing, passes off into a new 'now,' and that necessarily filled with content. ${ }^{10}$

But the phenomenological time field of the pure ego is by definition a phenomenologically reduced consciousness and since the phenomenological reduction,

... Forfeits apperceptive attachments not only to material objects and spatial relations but even its setting in cosmical time, [phenomenological time is revealed] . . . as the unitary form of all experiences within a single stream of experience (that of one pure ego). ${ }^{11}$
7. Ibid., p. 46.
8. Ibid., p. 48.
9. Ibid., p. 49.
10. Ibid., p. 219.
11. Ibid., p. 217. 
This means simply that the pure ego as the center of any one of its experiences is able to measure not only the three dimensionality of before, after, and at the same time, but the totality of the self-contained stream of temporal unities of experience. ${ }^{12}$

Consideration of a specific morphological-transcendent essence elucidates the features revealed by an object of essential intuition. Husserl's Formal and Transcendental Logic brings forth the "Kreutzer Sonata" as an example. Evidence reveals the sonata to be an ideal unity. The ideality of the sonata informs the whole composition as well as each individual note. This is spelled out in the relationship of the sonata viewed as a spiritual corporeality vis-à-vis its actual performance: each is a reproduction of the sonata. And yet the real reproductions of the individual notes are the source of the factual existence of the sonata.

Real reproductions involve the sounds pertaining to acoustic perception, the sounds that come from things pertaining to the senses extant only in an actual reproduction and the intuiting of it. ${ }^{13}$

But, when speaking of the "Kreutzer Sonata" as an essence, we are distinguishing all reproductions from the sonata itself. Thus, despite a potential infinite series of repetitions, the sonata, nonetheless, is given in each in the same manner as an identical, ideal object. Husserl says, that in a repetition of experiences in both retentive and protention, and with the synthesis of all possible recollections,

... there comes about an identity or sameness, moreover as an experience of this self sameness. [He concludes] . . . actually the effect of this identification is like that of an experience, except that an irreal object is not individuated in consequence of a temporality belonging to it originally. ${ }^{14}$

Again, what Husserl has shown is that a fundamental hiatus exists between essence and fact. But the view that essences must be of an inductive type hinges on the assumption that essences occupy a temporal location. However, it is precisely here that the separation between induction and eidetic reduction is adumbrated. The methodology of the naive realist is tied to referents which, themselves, are empirical and spatio-temporal. Furthermore, the naive realist subordinates the transcendent essences to naive appearances and the immanent essences are not allowed to emerge as correlates to transcendent essences. Thus, we are all sentenced to a simple observation which has more to do with "Simple Simon" than with elegance. Yet, Husserl's demand for an essence is a demand for apodictic certainty, not possible in the empirical realm. The certitude of the essence must establish itself as does the law of non-

12. Ibid., p. 219.

13. Edmund Husserl, Formal and Transcendental Logic, translated from the German by Dorion Cairns, Martinus-Nijhoff, The Hague (1969), p. 17.

14. Ibid., p. 156 . 
contradiction. It must offer self-evidence. The only mode available, then, is simple intuition from the reflexive unity of pure and empirical intuitions.

3 Faced with this evidence, critics still convinced that induction and eidetic reduction are compossible, make two new moves. The first is to deny a valid distinction between immanent and transcendent essences. The second is to argue that since transcendent essences provide evidence through spatio-temporal objects, such evidence cannot be apodictic. This, they argue, follows from the fact that the acts of perception could continue into infinity. To this objection we must repeat that the meaning of "transcendence" is not isomorphic to both the empirical object and transcendent essence. However, in a highly qualified sense when Husserl speaks of transcendent essences, he is considering evidence provided by their accompanying spatio-temporal objects. Therefore, we must ask, "In what sense are morphological essences transcendent?" And further, "Is this distinction between immanent and transcendent essences valid?"'

The separation is founded in different stand points of consciousness. Immanent essences are of the formal logical type, spond. ${ }^{15}$

... A type for which no possible sense data could possibly corre-

These have contents such as "proposition," "number," "order," "manifold," etc. Transcendent essences, on the other hand, are taken from the natural world. Content examples include "bodily shape," "man," "person," etc. But, immanent essences neither describe empirical objects nor are apprehended through the sensorium, although immanent essences are apprehended with the sensorium. These, like geometric concepts, are exact and ideal; they express something which one cannot physically see. In both content and origin they differ from essences having descriptive contents. The latter are transcendent essences drawn from simple intuition. The properties of transcendent essences are both vague and inexact as contrasted to the perfectly determined geometry of immanent essences. This is because transcendent essences are found in the flux of nature and are as imprecise as those concepts that describe nature:

.. . Notched, invented, lens-shaped umbelliform, and the like-simple concepts which are essentially and not accidentally inexact, and are therefore, also unmathematical. ${ }^{16}$

Now, all of this seems to play into the hands of Husserl's critics. That is, if transcendent essences accompany our perception of things, such perceptions could continue into infinity. Indeed, such a conclusion would effectively negate any claims concerning the apodicticity of transcendent essences.

15. Herbert Spiegelberg, The Phenomenological Movement, Volume I, MartinusNijhoff, The Hague (1969), p. 119.

16. Husserl, Ideas, p. 190 . 
Several issues are intertwined within this objection. First, how can it be legitimate to describe data taken from the natural order as essences? Second, what conditions must obtain in the achievement of apodictic certitude. Third, even if the distinction between immanent and transcendent essences is granted, is this on the grounds that immanent essences are mental constructions?

To set these matters right, one must first examine the manner in which immanent essences appear and then make the connection to transcendent essences. This is best handled by reviewing the conditions which follow the phenomenological reduction. They are as follows; first, the spatio-temporal world of facts with its attendant natural attitude toward those facts has been bracketed. Second, the products of this reduced sphere are essences, i.e., the products of a purified consciousness. Third, any further investigations or reductions are subsumed by such an a-priori consciousness. This suffices to explain the appearance of immanent essences which Husserl designates as

... Those which within the individual happenings of a stream of consciousness, and nowhere else, get particularlized influx-conditioned experiences of some sort or another. ${ }^{17}$

And with respect to the apodictic nature of essences he says

... The subject matter set down as real is then, fact, so far as its real content is individual, but it is eidetic necessity, insofar as it is the instancing of an essential generality. ${ }^{18}$

This leads to the distinction between immanent and transcendent essences as well as the legitimacy of attributing eidetic necessity to cases taken from nature:

The distinction between immanent and transcendent which holds good for individual objectivities holds on precisely similar lines for the corresponding essences. Thus, thing, spatial shape, movement, color of a thing, and so forth; also man, human feelings, soul, and physical experience, person, quality of character, and the like are transcendent essences. ${ }^{19}$

As a specific example of a case taken from nature, Husserl cites the proposition "All material things are extended." What gives this proposition eidetic validity? It can be taken as purely eidetic, that is, all reference to factual existence can be excluded as irrelevant. Hidden behind the "problem" of securing transcendent essences as eidetic objects is the attempt to interpret eidetic objects psychologically. However, this is a confusion which results from a false characterization of immanent es-

17. Ibid., p. 161.

18. Ibid., p. 154.

19. Ibid., p. 161. 
sences as "mental constructions." This is a psychologistic rendering of both types of essences which assumes them to be products of the

. . Momentary psychological intuition of colors and shapes. ${ }^{20}$

4 Having said this much, we are ready to consider the method of eidetic variation and the objection that evidence provided by eidetic consciousness is arbritary. This objection assumes two interdependent forms and is designed to show that objects of eidetic reduction are really types which emanate from a more refined form of induction. The objections are first that the method of variation is terminated before the gamut of possibles has been run through. That is, the object synthesizes just a limited range of evidence. Second, the essential nexus cannot offer itself as more than a presumptive unity of all and only those variants truly bearing the essentials of the essence in question. These objections can be refuted by an analysis of the operations of eidetic reduction. At the outset, since it is crucial to the entire discussion, we shall recapitulate the characteristics proper to the spatio-temporal object as contrasted to the transcendent essence. The spatio-temporal object is a real object. That is, it is particularized in space and time, susceptible to generation and corruption, and present as a hic et nunc. It has real content, shape and color; and it is the datum of sensory perception. The spatio-temporal object is transcendent, relative to the infinite number of sensory profiles it contains. As a consequence, its content is accidental. But, the spatio-temporal object is transformed through phenomenological reduction into a transcendent essence. It is not particularized in time and space as a hic et nunc. It has no real content because its existence is irrelevant-reality is not presupposed. It is the datum of unified intuition and is necessary because its reduced contents conform to a-priori essential laws. It is the actualization of a certain class which, of itself, is ideal and necessary.

5 Examination of a transcendent essence with particular attention given to Husserl's usage of "genus" is illustrative. As an example, I offer this empirical hic et nunc yellow object which confronts me-a sheet of yellow legal pad paper. This sheet of paper, as an existent, is irrevelant if my attention is directed to the yellowness of that paper. The yellowness of the paper represents the genus, yellow. The genus again is an ideal object. The demarcation of essences by genera is accomplished through an upward and downward movement which sets off both generality and specificity.

Every essence, whether it has content or is empty (and therefore purely logical), has its proper place in a graded series of essences, in a graded series of generality and specificity. The series necessarily possesses two limits that never coalesce. Moving downward we reach the lowest specific differences or, as we also say, the eidetic singularities; and as we move upwards through the essences of genus and species to a highest

20. Ibid., p. 165 . 
genus. Eidetic singularities are essences, which indeed have necessarily 'more general' essences as their genera, but no further specifications in relation to which they, themselves, might be genera (proximate or mediate, higher genera). Likewise that genus is the highest which no longer has any genus above it. ${ }^{21}$

Specifically, as concerns essences having a positive content, the distinction between highest genera and eidetic singularity is this: sensory quality, spatial shape, thing, and experience in general are highest genera; eidetic singularities are the essential elements pertaining to determinant things. Husserl upholds these content distinctions as he uses the terms, independent-concrete as against dependent-abstract. The former terms identify an eidetic singularity. The latter refer to highest or abstract genera. Genera, therefore, are employed as a means whereby eide are differentiated. As an example the essential genus, color, is different from the essential genus, sound. Pitch, timbre, and intensity are tonal qualities of the genus, sound. What characteristics are necessary for the eidos, yellow? Is the quality yellowness dependent upon this hic et nunc sheet of paper to be yellow? If such is the case, the yellow which I sight cannot be an essence; it must remain attached to an empirical object (the sheet) and it cannot be called apodictic. Eidetic reduction confirms my statement. For, if I ignore the hic et nunc reality of this sheet of paper, I may freely imagine other yellow objects. I may imagine yellow sunflowers, yellow houses, yellow trees, even other yellow sheets of paper. Or, I may imagine yellow patches of varying shapes and sizes. It is only when I attempt to imagine the eidetic singularity, yellow without any extension that I nullify the possibility of the united essence, yellow. All of this is summarized by Husserl in the following terms:

In the first case there arise relations possibly of one-sided or mutual dependence, and in respect of the eidetic and individual members that fall under the united essences there results the apodictically necessary consequence that there can be no members of the one essence that are not determined through essences which have at least generic community with the other essence. Sensory quality, for instance, points necessarily to some sort of difference in extensity. Extensity again, is necessarily the spread of quality united with it and enveloping it. ${ }^{22}$

If we return to our original eidetic singularity of yellow and then begin the variation of a series of eide, what we find is that an essential a-priori law is in operation. That is to say, yellow whether real or imagined must have extension. The independent content remains invariant. Indeed, each of the yellow "objects" within the series shows a connection, it shares the sameness of content which remains unchanged. Thus each is a transformation of that independent content, the exemplar, yellow. But these

21. Ibid., p. 64 .

22. Ibid., p. 161 . 
differences do not nullify (even in an infinite extension of such objects) their necessary relatedness as actualizations of that shared invariant form, yellowness. In other words, this specific eidos is a "logical actualization" of the ideal tone genus, yellow. The domains of color as extended and yellowness remain as invariant or independent content with reference to this variety of yellow ideal objects and all possible yellow ideal objects. Obviously, the subject who performs the process of free variation is involved in a finite process. But, in principle, those eide which remain possible share those invariant contents which have already been actualized. In other words, this same invariant form is applicable to all contents which can be conceived ad libitum. What this shows is that evidence provided by eidetic consciousness is not arbitrary. Nonetheless in the next section I shall consider a few loose ended objections which are bound up with the basic issues that I have tried to raise. These are: the relationship between transcendence and essences as synthetic objectives; the validity of claiming eidetic consciousness is a filling out process; and finally another argument set against the apodictic guarantee that attaches to morphologicaltranscendent essences.

6 Let us first consider the objection that essences are synthetic objectivities transcendent to the consciousness which has thematized them. Husserl's position clearly negates this assumption. First, he notes the difference between essential and empirical intuition. The data of empirical intuition exhibit color, shape, smoothness, etc., which are shown through perspective variation. A difference in principle obtains for essential intuition which presents the generic aspects through which a thing can show "color, smoothness, shape, simpliciter." The distinction is clear-cut: "The perspective variation though verbally similar to the perspected variable differs from it generically and in principle.",23 Husserl then notes that perspective variation is an experience. And experience gains its very possibility qua experience not as something spatial. "Although, spatiality belongs to the essence of the perspected variable, the possibility of spatiality is not possible as experience."24 This comes down to the cogitatio-cogitatum distinction. The cogitatio focuses upon immanent (reelen) phases of perception as contrasted with the focus of the cogitatum which is the matching complementary transcendental structure for perception. The one is at the pole of being as consciousness; the other is at the pole of being as reality. Being, as consciousness, exhibits these characteristics: it is given as plain insight and is immanent; it cannot exhibit aspects which may be varied perspectively; and finally, it necessarily generates its object. Being as reality is perspectively variable; reality exhibits different characteristics in its objects. Most importantly the real thing is not immanent, but contingent in human experience because it is

23. Ibid., p. 119.

24. Ibid. 
transcendent to the organs of outer perception, and rests on proofs of simple intuition.

... It can always happen that the further course of experience will compel us to abandon what has already been set down and justified in the light of empirical canons of rightness. ${ }^{25}$

But the objection, once again, turns upon the illicit use of the word, "transcendent" and is therefore demonstrably false.

The second objection is that eidetic consciousness is hardly suited to be described as a filling out process. Husserl claims eidetical research must concern that which "exists realiter," even though it is not yet actually experienced, or as yet can come to be given. The referent, here, is an undeterminable, or what Husserl calls a marginal field of factual experience. ${ }^{26}$ This field will be described and captured by essential insights based upon essences of generic community. This field is a correlate of thing experiences, but on essential grounds is filled out according to essential types.

7 Our final consideration represents still another convolution of the argument that apodicticity cannot be guaranteed for immanent essences. This argument assumes that some presently unknown features of the acts of willing or perception might not confirm the essence already discerned, but would suggest a destructive modification which would cancel the old and install a new, different and novel essence. This objection breaks down because these factors simply do not apply to any of the phenomenologically reduced spheres of consciousness. The sense and meaning datum of this purified sphere is a logical structure which is both identifiable, atemporal, and self-contained. It makes its appearance in a purely logical context which has "nullified" the world. Correlatively,

In every stream of experience certain ordered empirical connections, and accordingly also systems of theorizing reason which take their bearings from these would be excluded. Thus no real thing, none that consciously presents and manifests itself through appearances is necessary for the being of consciousness. ${ }^{27}$

Obviously, in this sphere, statements relating to movement into or out of a spatio-temporal system must be disallowed. But, since the objection, itself, appeals to causality, and then grafts itself onto the realm of eide, it simply does not suffice.

8 To sum up, we have looked at representative arguments which attempt to negate the apodictic nature of both immanent and transcendent-morphological essences. Typically these criticisms rely upon the demonstration that

25. Ibid., p. 131.

26. Ibid., p. 135.

27. Ibid., p. 137. 
a modal disjunction does not obtain between eidetic reduction and induction. Thus, the objects of eidetic reduction are (falsely) depicted as types which emanate from a more refined form of induction. This mistake is compounded by misconstruing Husserl's term, "transcendent" to mean that such "objects" are precluded from an adequacy of outer perception. The clear implication, here, is that essential "objects" are located in time and accordingly are inadequate as products of insight. The upshot is that eidetic reduction is characterized as an operation which is both arbitrary and has products which are, themselves, inadequate. At one point, we are in agreement with Husserl's critics. One cannot derogate the reality of an empirical and cultural world which antedates my personal existence as,

... simply a special case of various possible worlds and non-worlds which on their side are no other than correlates of the essentially possible variations of the ideal empirical consciousness. ${ }^{23}$

But this is not our present concern. The attempt to collapse Husserl's eidetic reduction into the inductive mode has been the point at issue. Our view is that such a move proceeds both from an incomplete assimilation of Husserl's ideas and an illegitimate rendering of his system. Specifically, these mistakes are rooted in the misuse of such highly technical notions as transcendent, content, form, adequacy, reduction, and induction. And, at bottom, these mistakes come from the refusal to accept the phenomenological and eidetic reductions on their own terms. In other words, essences are still treated as objects. The eidetic reduction is subsumed and subordinated to the canons of the natural real world. Ultimately, the failure to resolve these phenomenological difficulties is traceable to the culpable failure of not suspending the natural attitude.

I am indebted to Professor Antoinette Mann Paterson for her many helpful critical comments in the preparation of this paper.

State University College of New York at Buffalo

Buffalo, New York

28. Ibid., p. 134. 